\title{
ON THE DYNAMIC NATURE OF PHYSICS TEACHERS' PEDAGOGICAL CONTENT KNOWLEDGE
}

\author{
TOMÁŠ JANÍK' ${ }^{1}$ PETR NAJVAR', JAN SLAVÍK², JOSEF TRNA³ \\ ${ }^{1}$ Educational Research Centre, Faculty of Education, Masaryk University, \\ Brno, Czech Republic, ${ }^{2}$ Department of Art Culture, Faculty of Education, \\ The University of West Bohemia, Pilsen, Czech Republic, ${ }^{3}$ Department of \\ Physics, Faculty of Education, Masaryk University, Brno, Czech Republic
}

\begin{abstract}
This study focuses on the role of teachers' pedagogical content knowledge $(P C K)$ in transforming subject matter in physics instruction (at lower-secondary school). The purpose of the present study is to investigate the nature of teachers' pedagogical content knowledge. Video recordings were analysed of 27 lessons taught by 8 lowersecondary school teachers on the topic "composition of forces". A typology of content representations was developed inductively. The findings show that teachers use various types of content representations. These illustrate the dynamic nature of teachers' pedagogical content knowledge, which is documented using the example of a teacher who combines various types of representation flexibly when introducing the concept "composition of forces".
\end{abstract}

Key words: content representation, pedagogical content knowledge, physics teaching, video study

\section{Introduction}

The present study contributes to the body of research on teachers' pedagogical content knowledge (PCK), which is one of the most prominent fields of AngloAmerican educational research (see Kansanen; van Dijk; Pepin in this issue). In the context of a European research tradition, this field is known as the study of didactical transformation - in German didaktische Transformation (Kansanen, 2002). The study of physics teachers' PCK is embedded in a broader research project - the CPV Video Study of Physics - which is carried out at the Educational Research Centre, Faculty of Education, Masaryk University in Brno, Czech Republic (see Najvar et al. 2009; Najvar, Najvarová \& Janík in this issue).

This study is aimed at the role of teachers' PCK in transforming subject matter in physics instruction (at lower-secondary school). Video recordings of 27 lessons taught by 8 teachers on the topic "composition of forces" were analysed within the CPV Video Study project that aimed to document and describe everyday teaching of 
Physics in Czech lower-secondary schools. A typology of content representations was developed inductively. The findings are used to illustrate the dynamic nature of teachers' PCK.

\section{Theoretical background}

Shulman $(1986 ; 1987)$ succeeds in demonstrating that teachers have a specific form of knowledge which is different from that of a subject-matter expert. This distinction dates back to Dewey, who points out that a scientist's knowledge of the subject matter is different from the specialized understanding of the subject matter of the teacher, who is interested in "how his own knowledge of the subject matter may assist in interpreting the child's needs and doings, and determining the medium in which the child should be properly directed" (Dewey, 1902, p. 286, cited in Tsu, 2004, p. 52). Recent research confirms Dewey's insight, which is reflected in a study by Grossman, Wilson, and Shulman: "While some of what teachers need to know about their subjects overlaps with the knowledge of scholars of the discipline, teachers also need to understand their subject matter in ways that promote learning. Teachers and scholars have different primary goals. Scholars create a new knowledge in the discipline. Teachers help students acquire knowledge within a subject area. These differing goals require related but distinct understanding of subject matter" (1989, pp. 24-25). The specific kind of knowledge the teacher has, is PCK - the category, which is "most likely to distinguish the understanding of the content specialist from that of the pedagogue"(Shulman, 1987, p. 8). This knowledge is what distinguishes a chemistry teacher from a chemist, a mathematics teacher from a mathematician.

Shulman sees PCK as a specific category of knowledge, "which goes beyond knowledge of subject matter per se to the dimension of subject matter knowledge for teaching" (1986, p. 9). PCK is the basis for teaching expertise. According to Shulman, teachers' expertise lies "in the capacity of the teacher to transform the content knowledge he or she possesses into forms that are pedagogically powerful and yet adaptive to the variations in ability and backgrounds presented by the students" (1987, p. 15). PCK represents "the blending of content and pedagogy into an understanding of how particular topics, problems, and issues are organized, represented, and adapted to the diverse interests and abilities of learners and presented for instruction" (Shulman, 1987, p. 8).

In this special form of teacher's professional knowledge and understanding, there are two crucial aspects: a) knowledge of representations of subject matter, b) understanding of specific learning difficulties and student's preconceptions (cf. Driel et al., 1998). Marks (1990) extends Shulman's model by including knowledge of subject matter per se and knowledge of media for instruction in PCK. Cochran, DeRuiter and King (1993) take the constructivist view of teaching and prefer the term pedagogical content knowing (PCKg) to pedagogical content knowledge (PCK). They point out the dynamic nature of pedagogical content knowing, which they define as "... a teacher's integrated understanding of four components of pedagogy, 
subject matter content, students characteristic, and the environmental context of learning" (Cochran et al., 1993, p. 266). According to Fernández-Balboa and Stiehl (1995) PCK consists of five components: subject matter, the students, instructional strategies, the teaching context, and one's teaching purposes.

As pointed out in the study by Driel et al. (1998, p. 677), there is no universally accepted model of PCK. On the other hand, all the authors cited accept Shulman's two key elements (knowledge of representation of subject matter and understanding of specific learning difficulties and student preconceptions).

$$
\begin{gathered}
\text { Pedagogical content knowledge - ways of knowing } \\
\text { how to represent the content }
\end{gathered}
$$

A teacher's knowledge and understanding of the content to be taught is a prerequisite of effective teaching. Teacher's pedagogical content knowledge is demonstrated in various ways, such as "the most powerful analogies, illustrations, examples, explanations, and demonstration - in a word, the ways of representing and formulating the subject that make it comprehensible to others" (Shulman, 1986, p. 9). To illustrate what is ment by PCK we present teacher's knowledge about a commonly used analogy in science education. As Loughran, Berry, and Mulhall explain, the reason for presenting an analogy is to draw parallel between new ideas and specific/similar situation. For example, "although something may appear to be made up of one thing - like a pipe is made up of one piece of metal - it is really the combination of lots of small things. This can be analogous to a jar of sand. From a distance it looks like one thing, but up close you can see the individual grains of sand" (Loughran, Berry, \& Mulhall, 2006, p. 34).

The dynamic nature of PCK is manifested in how the teacher approaches pupils of different ages when teaching particular subject matter, how he manages to take students preconceptions and learning difficulties into account etc. The success of teaching also depends on means of communication that the teacher deploys in managing interaction with students. These include common language means or symbolic tools: figures, formulae, specific motoric activities (e.g. in art or sport), drawings, diagrams, etc. - content representations. Content representations play an important role in introducing, demonstrating, explaining, and manipulating content to be taught. There are differences among individual subjects as well as among individual teachers of a subject in what content representations are used in instruction (Leinhardt \& Smith, 1985).

The meaning is to be interpreted by the student from the content representation. The result of this interpretation is that the student should be able to grasp the content. Once the student recognises the relationships between content representation and meaning, i.e. he can use his own representation to express, convey and think about the content, he demonstrates his knowledge. The teacher should formulate his representation in such a way that the student understands the content - he grasps the meaning correctly and without serious difficulties. The teacher must take the accuracy of the content into account. As shown in Fig. 1, 
teacher's content representation need to be in accordance with (1) analogical content representation of an expert in the field and it should respect (2) student's predispositions and learning possibilities (cp. van Dijk, Kattmann, 2007).

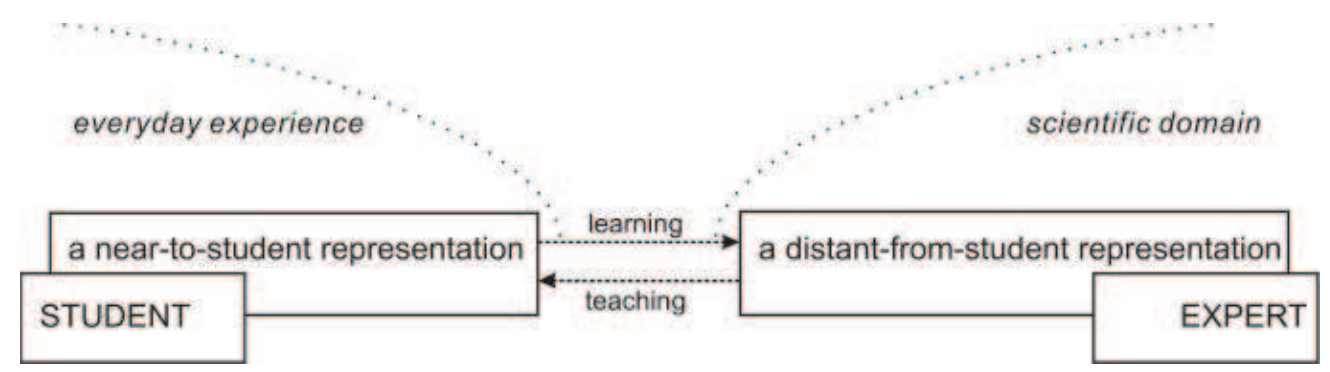

Figure 1: Learning-teaching, student-teacher and content representations

\section{The nature of a teacher's pedagogical content knowledge}

Much of the current research on teachers' knowledge focuses on its nature. Despite a lack of consensus about the nature of teachers' PCK, there is some evidence that this knowledge is value-laden (Gudmundsdottir, 1990). Values in knowledge operate as a kind of filter which plays a role in decision making as to what is important in teaching, what questions should be asked etc.

Gudmundsdottir (1995) demonstrates the narrative nature of a teacher's PCK. Teaching is seen as an interpretative and reflexive activity in which narration (as a specific way of knowing) plays an important role. Narration makes it possible to understand the world in a new way. A study of experienced teachers has shown that they intuitively use narratives to bring order to what they consider a disjointed curriculum (Gudmundsdottir, 1991). Teachers use narratives as a tool for structuring subject matter. According to this author, the teacher's experience is transformed into his PCK through the narrative dialogue of reflection and interpretation. "The study of teachers' stories and narratives brings us right to the heart of pedagogical content knowledge, in all its varied and richness" (Gudmundsdottir, 1995).

In a study by Driel, Veal and Janssen (2001) attention is paid to the integrative nature of knowledge. In a number of other studies evidence is presented that $P C K$ is implicit and of practical nature (Driel et al., 1998).

One of the distinctive features of the dynamic nature of this knowledge is manifested in how the teacher approaches pupils of different ages when teaching particular content, how he manages to take pupils' preconceptions and learning difficulties into account etc. The quality of a teacher's PCK lies in its regard both to the content and to its possible pedagogical representations with regard to the pupils. The dynamic quality of PCK is due to the growth in teacher's capacity to communicate content because they know their subject and students better. An experienced teacher is able to see the "curricular potential" of learning material, and so has a number of possibilities for how to deal with the content pedagogically 
- how much time is spent on particular aspects of the content; what the timing is when the content is introduced and elaborated; how it is (re)presented, what questions are asked, what the students' role is etc. Wilson, Shulman and Richert (1987) speak about the teacher's "150 different ways of knowing the content". These open up to him when he is pursuing the "didactic analysis of subject matter" (Klafki, 1958). If a teacher understands the subject matter pedagogically, he is able to take students' needs into consideration. He is "able to elucidate subject matter in new ways, reorganize and partition it, clothe it in activities and emotions, in metaphors and exercises, and in examples and demonstrations, so that it can be grasped by students" (Shulman, 1987, p. 13).

\section{Methodological considerations}

When Shulman introduced his concept of PCK, there were relatively few demonstrations of what PCK was or what it looked like. Research in the 1980s and 1990 s is primarily of an exploratory character and aims at identifying, documenting, and portraying teacher's PCK in different school subjects, in different types of schools and at different levels of schooling; comparative studies exploring PCK in teachers-beginners and teachers-experts are common (e.g. Gudmundsdottir \& Shulman, 1987). More recent research focuses on characteristic features of this knowledge - specificity, narrativeness, implicitness, adaptability etc. (e.g. de Jong, 2003). Gradually, longitudinal research is also beginning to develop, the aim of which is to monitor and document the evolution of the teacher's PCK (Seymour \& Lehrer, 2006). Related to attempts at evaluating the teacher's professional competence, methodological techniques have been developed recently which enable the measuring of the level of PCK (Krauss et al., 2008).

As for approaches, methods and techniques applied in the research of PCK, the breadth of their spectrum corresponds to the complexity of the phenomenon examined. Besides quantitative approaches (primarily based on psychometric methods), there has been clear development in qualitative approaches (particularly those of an interpretivist or hermeneutic nature). Most of the research is based on the use of combination of several methods (eclectic methodology), and this serves to meet the specific character of PCK. For example, methods based on the observation of teaching offer only a partial view of the teacher's PCK, as this is an inner construct which can only be gathered to a limited extent from its external manifestations. It is therefore necessary to ask the teachers questions - examine their articulation of the knowledge. Furthermore, PCK is quite an implicit matter - teachers often lack vocabulary to express it, hence research is often based on a combination of direct or video-based observation, stimulated recall and narrative interview. Since the teacher's PCK forms a certain conceptual structure, techniques like conceptual mapping and concept structuring are employed (Loughran, Berry, \& Mulhall, 2006).

In studying PCK a number of methods, techniques and instruments have been used (e.g. Baxter \& Lederman 1999; Loughran, Mulhall, \& Berry 2004). As our 
intention was to investigate teacher's PCK as it is demonstrated in real teaching (PCK-in-action), methods based on qualitative analysis of lesson transcripts and video recordings are considered suitable for our purposes. In this study, we try to identify teacher's PCK "beyond" the representations of content (analogies, illustrations etc.) that a teacher uses in teaching. Content representation can be observed and recorded (e.g. by means of video). Video recordings of content representation become fact, which can then be analysed within a specific theory.

\section{Present study on the pedagogical content knowledge of physics teachers}

\section{Purpose and research questions}

The present study focuses on the nature of a teacher's PCK. The purpose is to analyse one of the features of this knowledge, i.e. its dynamic nature. Video recordings of lessons given by Czech lower-secondary school teachers of physics have been used for purposes of analysis. The research questions are: What types of representations of the concept "compositions of forces" are used by teachers and what can be inferred concerning their PCK? How is the dynamic nature of teacher's PCK demonstrated in teaching? From a methodological point of view, the focus lies on illustration and discussion of the potential of video case study as a means of presenting teacher's PCK.

\section{Method - data collection and analysis}

The research of PCK is a part of the CPV Video Study of Physics (Janík, Miková, Najvar \& Najvarová 2006). This is based on analysis of video recordings of 27 lessons on the topic "composition of forces", taught by 8 teachers at lower-secondary schools in Brno, Czech Republic (see Table 1). Following the lead given by the TIMSS and IPN video studies (Jacobs et al., 2003; Seidel et al., 2005), lessons were recorded using a standardised procedure with two video cameras. One camera captured the activity of the teacher and his/her interaction with the immediate surroundings (the blackboard, the first row of students), while the other camera aimed to capture the activity of the class (the majority of the students).

Following Shulman's definition of PCK as comprising the "most useful forms of representation of these ideas, the most powerful analogies, illustrations, examples, explanations, and demonstrations-in a word, the ways of representing and formulations the subject that make it comprehensible to others" $(1987$, p. 8), we identified those teaching situations in which various representations of the concept "composition of forces" could be observed. We used Videograph software (Rimmele, 2002). 
Table 1: An overview of lessons analysed

\begin{tabular}{|c|c|c|c|c|c|c|c|}
\hline \multicolumn{3}{|c|}{ Teacher } & \multicolumn{2}{|c|}{ Pupils } & \multicolumn{3}{|c|}{ Subject matter } \\
\hline 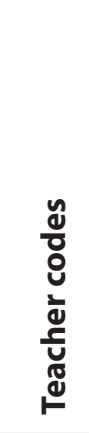 & 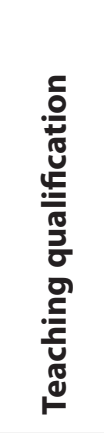 & 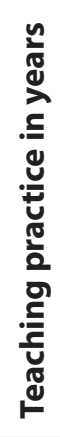 & 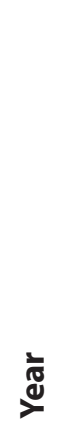 & 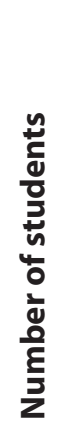 & $\frac{4}{0}$ & 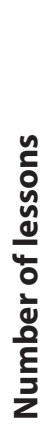 & 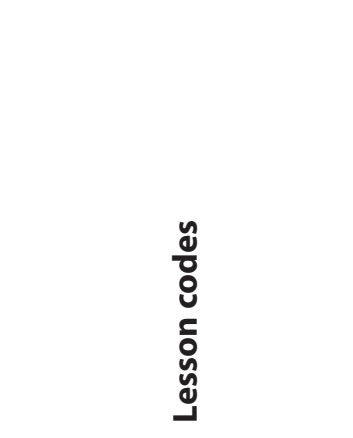 \\
\hline A & $\begin{array}{l}\mathrm{FY} / \\
\mathrm{MA}\end{array}$ & 2 & 7. & 20 & \multirow{8}{*}{ 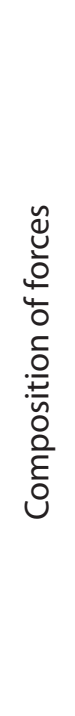 } & 4 & $\begin{array}{l}\text { FyS_A1, FyS_A2, } \\
\text { FyS_A3, FyS_A4 }\end{array}$ \\
\hline B & $\begin{array}{l}\text { FY/ } \\
\text { MA }\end{array}$ & 17 & 7. & 18 & & 4 & $\begin{array}{c}\text { FyS_B1, FyS_B2, FyS_B3 } \\
\text { FyS_B4 }\end{array}$ \\
\hline E & FY/TE & 27 & 6. & 21 & & 2 & FyS_E1, FyS_E2 \\
\hline $\mathrm{H}$ & $\mathrm{FY} / \mathrm{TE}$ & 4 & 7. & 23 & & 3 & FyS_H1, FyS_H2, FyS_H3 \\
\hline I & $\mathrm{FY} / \mathrm{TE}$ & 3 & 7. & 16 & & 3 & FyS_I1, FyS_I2 FyS_I3 \\
\hline J & $\begin{array}{l}\text { FY/ } \\
\text { MA }\end{array}$ & 28 & 7. & 29 & & 3 & FyS_J1, FyS_J2 FyS_J3 \\
\hline L & $\begin{array}{l}\mathrm{FY} / \\
\mathrm{MA}\end{array}$ & 7 & 7. & 27 & & 4 & $\begin{array}{l}\text { FyS_L1, FyS_L2, } \\
\text { FyS_L3, FyS_L4 }\end{array}$ \\
\hline$M$ & $\begin{array}{l}\text { FY/ } \\
\text { MA }\end{array}$ & 3 & 7. & 23 & & 4 & $\begin{array}{l}\text { FyS_M1, FyS_M2, } \\
\text { FyS_M3, FyS_M4 }\end{array}$ \\
\hline
\end{tabular}

Using an inductive approach combining open coding (Strauss \& Corbin, 1999) and qualitative content analysis (Mayring, 1983) a typology was developed for the representation of "composition of forces". Table 2 gives authentic examples of PCK-in-action which were identified in the lessons analysed. Finally, we present a case study providing an insight into the dynamic nature of PCK (Table 3). 
Table 2: Types of representations of "composition of forces" identified in lessons

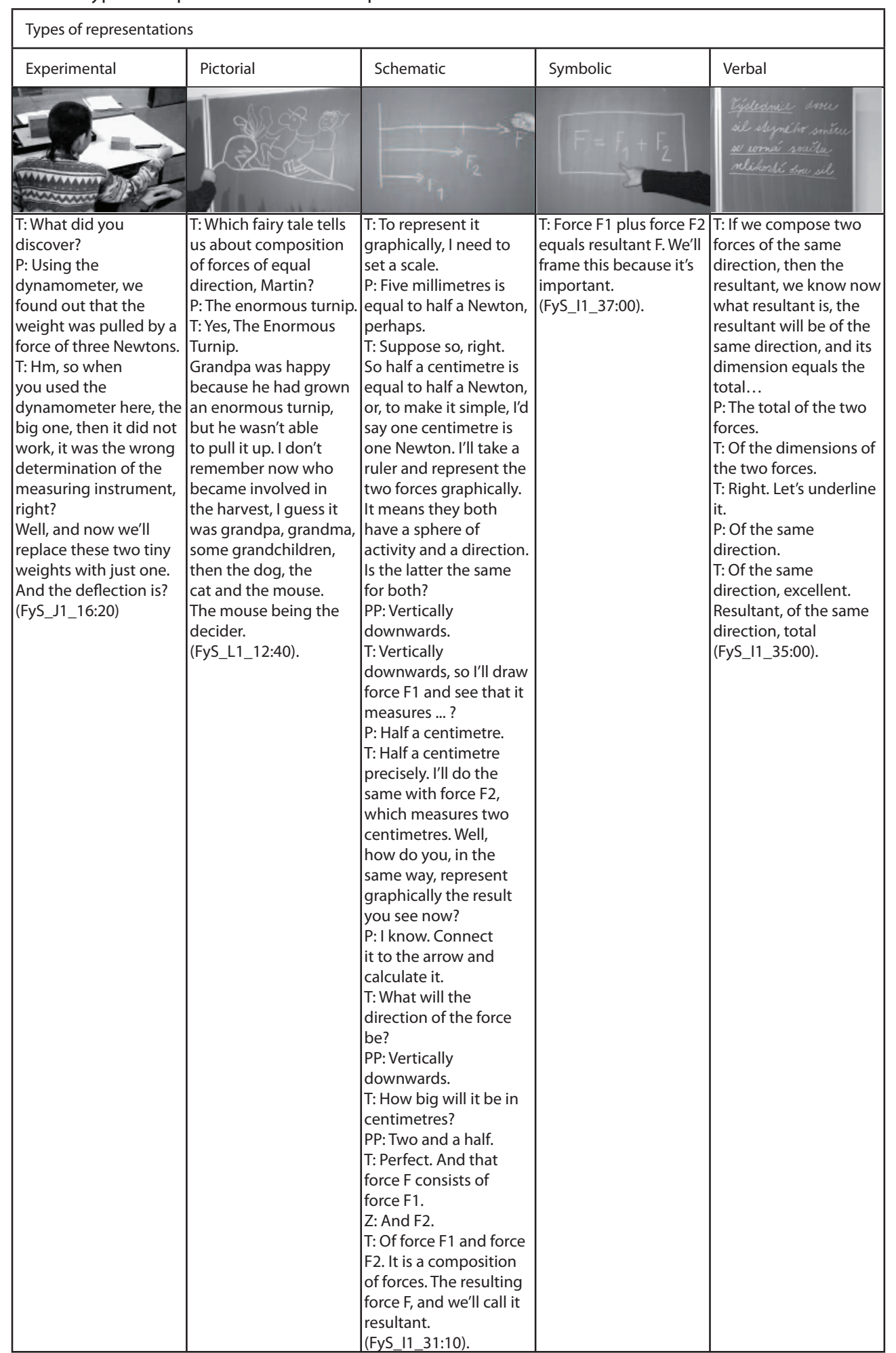




\section{Results}

Which representations of the concept "composition of forces" are used by physics teachers and which PCK can be identified in them?

In individual lesson phases different representations of "composition of forces" were used. Representations were frequently found in the lesson phases developing new content, securing/practicing and applying/intensifying (for definitions see Seidel, Prenzel, \& Kobarg, 2005). Based on analysis of the video recordings a typology of representations was developed (Table 2), comprising the following types of representation: experimental, pictorial, schematic, symbolic and verbal.

Various representation types differ in the degree to which they are abstract. Experimental representations arise from the real interactions of teacher and pupils; in pictorial and schematic representations imagination is used more; in symbolic representations another symbolic system is used (e.g. mathematical symbols), which is more demanding on pupils' abstract thinking (cf. Bruner, 1968). Verbal representations are typically definitions enabling the learner to grasp abstract concepts.

1. Experimental representations (experiments) were in most cases demonstration experiments performed by the teacher. In the lessons observed we did not find a single situation where the introduction of the concept "composition of forces" was performed by the pupils themselves in the process of independent or directed heuristic exploration of the phenomena. Demonstration experiments were in all cases accompanied by the teacher's verbal commentary (exposition); only rarely did teachers provide an opportunity for pupils to comment in their own words on what was going on during the experiment (dialogue with the class). Differences among representations were brought about by different kinds of teaching aids, the design of the experiment and the procedure for its performance.

2. Pictorial representations were mainly in the form of pictures (e.g. tugging the turnip; dogs pulling a sledge; tug-of-war). The teachers drew these on the blackboard or used pictures from the textbook. These pictorial representations enhance the building up of images of the object under investigation. A real object perceived with the senses by a number of redundant features (shape, colour, etc.) is simplified in the picture and the main system features of the phenomenon are emphasised. Some pictures were also used for motivation, such as tugging the turnip (see Table 2). Pictorial representation also had substantial potential for creating variations, which was exploited in lessons to a greater extent than experimental representations. The reason for this may be that choosing a picture in a textbook or drawing it is less difficult and time-consuming than designing an alternative experimental apparatus for the pupils. 
3. Schematic representations appeared in teaching in the form of graphic illustration (e.g. composition of vectors). These representations are the step which follows the examination of a specific natural object or phenomenon to its abstract idea (model). What they require of pupils is a higher level of abstraction.

4. Symbolic representations are the most abstract way of depicting an object or phenomenon. The law of composition of forces is represented in the most concise form using the mathematical symbols of vector algebra - addition of vectors (see Table 2). The teachers in our investigation respected the pupils' level of abstraction in the authentication of vector symbols and therefore did not use the symbol of vector force as it really is.

5. Verbal representations principally took the form of definitions or descriptions of phenomena. The following statement is an example of a definition: "The resultant of two forces in the same direction equals the sum of their magnitude" (see Table 2). This is caused by a high density of abstract concepts, which are often new and not very well established (e.g. "resultant, force, sum, equality, magnitude" in our example). In the lessons observed we were most aware of the deductive method, which leaves little space for pupils' own exploratory activities. Descriptive verbal representations are used chiefly for reports of experiments, the procedure of quantity measurements (e.g. measurement of force) etc. Teachers did not devote the same attention to these representations as to representations of verbal definition. However not all teachers' verbal comments can be considered as verbal representation: very often they are merely comments, which do not function as representations as such but are used to accompany demonstrative experiments, schematic illustrations or to deduce mathematical relationships etc. A specific role is played by narration, which is used by teachers as an instrument to structure subject matter (see Gudmundsdottior, 1995) and as a motivation technique.

\section{How is the dynamic nature of teachers' PCK demonstrated in instruction?}

In lessons FyS_J1, FyS_J2, FyS_J3, given by the teacher Jana (see Table 1), various representations of the concept "composition of forces" were combined flexibly. This particular teacher fell in the category of expert teachers ${ }^{3}$ and she volunteered to participate in the follow-up study. We carried out a stimulated-recall interview with her about a selected situation. There we played a video recording of short situations in her lessons and her task was to comment on them. The aim was to get a better insight into her thinking about the content, thoroughly examine the relationships among representations that she used in her teaching, and to improve our understanding of her PCK.

We presented the episode as a video case study (see Table 3), providing evidence

3 Criteria for identifying teacher expertise included: more than five years of teaching practice, respected in the group of peers, indicators of performance etc. (e.g. Palmer et al., 2005). 
of demonstrations of the dynamic nature of PCK (the middle column), which is based on the use of different representations of the concept "composition of forces" (left-hand column). The transcript of the interview (right-hand column) gives us a glimpse of the teachers' PCK. 
Table 3: Video case study of teachers' PCK

\begin{tabular}{|c|c|c|}
\hline \multicolumn{3}{|c|}{$\begin{array}{l}\text { Video case study "Different ways of knowing how to teach } \\
\text { the topic of composition of forces" }\end{array}$} \\
\hline Representation - examples & Teachers' PCK beyond... & \multirow{4}{*}{$\begin{array}{l}\text { From interview with teacher Jana } \\
\text { RESEARCHER: When we had looked } \\
\text { through your lessons, we found different } \\
\text { ways of speaking about the force. You } \\
\text { began with an experiment followed by } \\
\text { fairy tale The Enormous Turnip. What was } \\
\text { your purpose of including the fairy tale? } \\
\text { TEACHER. ...it was motivation, and making } \\
\text { use of a thousand-year-long experience, } \\
\text { and essentially making use of the } \\
\text { cooperation in the tale. }\end{array}$} \\
\hline & \multirow[t]{2}{*}{$\begin{array}{l}\text { Teachers' PCK as } \\
\text { experimental demon- } \\
\text { stration (made by teachers } \\
\text { and/or pupils). }\end{array}$} & \\
\hline Experimental & & \\
\hline & \multirow{3}{*}{$\begin{array}{l}\text { Teachers' PCK as the story "The } \\
\text { Enormous Turnip". }\end{array}$} & \\
\hline & & $\begin{array}{l}\text { RESEARCHER: Then the vectors got into it, } \\
\text { functioning as? }\end{array}$ \\
\hline Pictoral (narrative) & & $\begin{array}{l}\text { TEACHER: It is graphical representation of } \\
\text { composition of forces, and numerical and } \\
\text { verbal. It is assembled here from several } \\
\text { points of view. ... the pupil should visualize } \\
\text { all those pictures when speaking about } \\
\text { composition of forces. When they write }\end{array}$ \\
\hline & \multirow[t]{2}{*}{$\begin{array}{l}\text { Teachers' PCK as a figure of } \\
\text { vector addition. }\end{array}$} & $\begin{array}{l}\text { this formula, or I write it, or wherever they } \\
\text { see it, they should instantly verbalize this } \\
\text { sentence and visualize these oriented line } \\
\text { segments, vectors. We don't call them } \\
\text { vectors for now, not until secondary school. } \\
\text { For us, it is now the oriented line segment. }\end{array}$ \\
\hline Schematic & & $\begin{array}{l}\text { RESEARCHER: And now the pupils' task } \\
\text { was to interconnect the different ways, } \\
\text { or realize that they are interconnected in } \\
\text { some way...? }\end{array}$ \\
\hline Symbolic & $\begin{array}{l}\text { Teachers' } P C K \text { as symbolic } \\
\text { formula } F=F 1+F 2 \text {. }\end{array}$ & $\begin{array}{l}\text { TEACHER: ... that we can describe the } \\
\text { situation physically. That is the physical } \\
\text { expression of the situation, of the tale. This } \\
\text { is how physicists describe it, and physics } \\
\text { does not go without mathematics, so } \\
\text { it's for them to see the relation between } \\
\text { the physical action and its mathematical } \\
\text { formulation, and the mathematical } \\
\text { formulation can be expressed by a }\end{array}$ \\
\hline 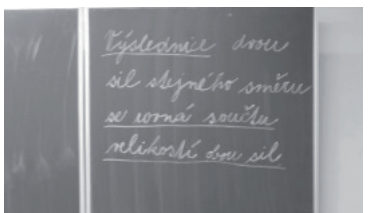 & \multirow[t]{3}{*}{$\begin{array}{l}\text { Teachers' PCK as the definition } \\
\text { "The magnitude of the } \\
\text { resultant of two forces of the } \\
\text { same direction equals the } \\
\text { summation of the magnitudes } \\
\text { of the original forces". }\end{array}$} & $\begin{array}{l}\text { RESEARCHER: Is there anything you would } \\
\text { like to add? } \\
\text { TEACHER: Well, it is about how many ways } \\
\text { we manage to complete in a lesson. }\end{array}$ \\
\hline & & \\
\hline & & \\
\hline
\end{tabular}




\section{Conclusions and discussion}

If the knowledge of teachers seems to be to a certain extent implicit (see Kansanen in this issue), the potential for professional sharing knowledge is limited. That implies a question: How can we turn a teacher's knowledge into words how can we verbalize it? In this study we attempt to illustrate means by which to capture and portray the teacher's PCK. The search for suitable methods of PCK research is motivated by the effort "to develop codified representation of practical pedagogical wisdom of able teacher" (Shulman, 1987, p.11) and thus contributes to the developing of a knowledge base for teaching. Video seems to be a powerful tool for capturing $P C K$ because of its dynamic and practical nature.

In the lessons studied, various representations of "composition of forces" were found (experimental, symbolic, verbal, pictoral, schematic). Representations were frequently found in the phases developing new content, securing/practicing and applying/intensifying. A teacher knows various ways (representations) of teaching a particular concept, which is a prerequisite for him to adjust the content to the students' abilities. The individual types of representations were often integrated into more complex wholes. The representations appeared in classes in various combinations, from which the dynamic nature of the teacher's PCK can be concluded. The dynamic nature of PCK - the teacher possesses different skills for teaching a particular concept, which enables him/her to adjust the content to the students' abilities. However, further research into other possible manifestations of this dynamism is desirable.

Based on their education and their experience teachers have a PCK which determines the repertoire of specific concept representations they use. Different types of representation seem to be interconnected in the teacher's mind, which enables him to employ them flexibly in teaching and thus support the student's understanding of the content. This, too, shows the dynamic nature of the teacher's PCK. When teaching, teachers employ multiple representations of the content this was also proved true of Czech teachers in the 1999 TIMSS Video Study (Roth et al., 2006). These are mostly various representations of the same content (Table 3). Through this finding, we are confronted with a very interesting problem from the pedagogical point of view, the problem of synonymy in (re)presenting content. In multiple representations, different ways of knowing the content are intertwined. To use multiple representations in the lesson is to acknowledge different student's learning styles (visual, auditory, kinaesthetic). How the teacher's sensitivity to student's learning styles influence his choice of different content representations? How the teacher's own learning style influence his choice of representations for teaching specific content? These are relevant questions for a reserach study focused on the interaction between teachers' content knowledge, PCK, knowledge about students etc.

During this study more questions emerged that should be paid heed to in the future. What is the spectrum of representations used by different teachers under comparable conditions and circumstances in the same forms? What is 
the spectrum of representations used by one teacher under different conditions and circumstances? What is the mechanism by which a certain representation is launched, and which factors determine its rise? How does a certain representation develop, and which factors influence changes within it? What is the influence of certain representations on the fulfilment of teaching objectives? If we want to start looking for answers to these questions, first we have to create an adequate research methodology. Our experience has shown that analysis of video recordings of lessons can play an important role in this methodology. What are the merits of using the methodological technique presented here, and what are its constraints when studying and documenting the teacher's PCK? From our experience we can formulate the following conclusions. PCK is a practical knowledge (Driel et al., 1998) - teachers' PCK is brought to light in action - which is why we use video to examine PCK from its genuine manifestations in teaching (which include representations of the content). This is where analyses of transcripts or video recordings of lessons can be used to good effect. The video case study seems to be a powerful form of representing and communicating teachers' PCK. This tool makes it possible to capture the accumulated wisdom of teaching practice, and supports the transfer of research knowledge between researchers and teachers.

\section{Acknowledgements}

The study was carried out within financial support from the Ministry of Education, Youth and Sports of the Czech Republic, by Grant No. LC06046: "Centre for Basic Research on Schooling".

\section{References}

Baxter, J.A. \& Lederman, N.G. (1999). Assessment and Measurement of Pedagogical Content Knowledge. J. Gess-Newsome, \& N.G. Lederman (Eds.), Examining Pedagogical Content Knowledge: The Construct and its Implications for Science Teaching (pp. 147-161). Dordrecht, Boston, London: Kluwer Academic Publishers.

Bruner, J.S. (1968). Processes of Cognitive Growth: Infancy. Worcester MA: Clark University Press.

de Jong, O. (2003). Exploring Science Teachers' Pedagogical Content Knowledge. In Psillos, D., Kariotoglou, P., Tselfes, V., Hatzikraniotis, E., Fassoulopoulos, G., \& Kallery, M. (Eds.), Science Education Research in the Knowledge-Based Society (pp. 373-381). Dordrecht, Boston, London: Kluwer Academic Publishers.

Dewey, J. (1902). The Child and the Curriculum. In J.A. Boydston (Ed.), John Dewey: The Middle Works, 1899-1924, Volume 2: 1902-1903 (pp. 273-291). Carbondale: South Illinois University Press.

Fernández-Balboa, J.M. \& Stiehl, J. (1995). The Generic Nature of Pedagogical Content Knowledge among College Professors. Teaching and Teacher Education, 11, 293-306. 
Grossman, P.L. (1990). The Making of a Teacher: Teacher Knowledge and Teacher Education. New York: Teacher College Press.

Gudmundsdottir, S. (1995). The Narrative Nature of Pedagogical Content Knowledge. In H. McEwan \& K. Egan (Eds.), Narrative in Teaching, Learning and Research (pp. 24-38). New York: Teachers College.

Gudmundsdottir, S. (1990). Values in Pedagogical Content Knowledge. Journal of Teacher Education, 41(3), 44-52.

Gudmundsdottir, S. \& Shulman, L.S. (1987). Pedagogical Content Knowledge: Teachers'Ways of Knowing. In Å.L. Strømnes, \& N. Søvik (Eds.), Teachers Thinking. Perspectives and Research (pp. 51-83). Trondheim: Tapir.

Jacobs, J., Garnier, H., Gallimore, R., Hollingsworth, H., Bogard Givvion, K., Rust, K., Kawanka, T., Smith, M., Wearne, D., Manaster, A., Etterneek, W., Hiebert, J., Stigler, J., \& Gonzales, P. (2003). Third International Mathematics and Science Study 1999 Video Study Technical Report. Volume 1: Mathematics. Washington, DC : National Center for Education Statistics. Institute of Education Statistics, U. S. Department of Education.

Janík, T., Miková, M., Najvar, P. \& Najvarová, V. (2006). Unterrichtsformen und -phasen im tschechischen Physikunterricht: Design und Ergebnisse der CPV Videostudie Physik. [Forms and Phases in Physic Instruciton in the Czech Republic: Design and Results of CPV Video Study of Physics]. Zeitschrift für Didaktik der Naturwissenschaften, 12(1), 219-238.

Kansanen, P. (2002). Didactics and its Relation to Educational Psychology: Problems in Translating a Key Concept across Research Communities. International Review of Education, 48(6), 427-441.

Klafki, W. (1958). Didaktische Analyse als Kern der Unterrichtsvorbereitung [Didactical Analysis as the Core of Lesson Planning]. Deutsche Schule, 10, 450471.

Krauss, S., Brunner, M., Kunter, M., Baumert, J., Blum, W., Neubrand, M. \& Jordan, A. (2008). Pedagogical Content Knowledge and Content Knowledge of Secondary Mathematics Teachers. Journal of Educational Psychology, 100(3), 716-725.

Leinhardt, G., \& Smith, D.A. (1985). Expertise in Mathematics Instruction: Subject Matter Knowledge. Journal of Educational Psychology, 77(3), 247-271.

Loughran, J., Berry, A., \& Mulhall, P. (2006). Understanding and Developing Science Teachers' Pedagogical Content Knowledge. Rotterdam: Sense Publishers.

Loughran, J., Mulhall, P., \& Berry, A. (2004). In Search of Pedagogical Content Knowledge in Science: Developing Ways of Articulating and Documenting Professional Practice. Journal of Research in Science Teaching, 41(4), 370-391.

Mayring, P. (1983). Qualitative Inhaltsanalyse. Grundlagen und Techniken [Qualitative Content Analysis. Foundations and Techniques]. Weinheim und Basel: Beltz.

Najvar, P., Janík, T., Janíková, M., Hübelová, D., \& Najvarová, V. (2009). CPV Video Study: Comparative Perspective on Teaching in Different School Subjects. In T. Janík \& T. Seidel (Eds.), The Power of Video Studies in Investigating Teaching and Learning in the Classroom (pp. 103-119). Münster: Waxmann Verlag.

Palmer, D.J., Stough, L.M., Burdenski Jr, T.K., \& Gonzales, M. (2005). Identifying 
Teacher Expertise: An Examination of Researchers' Decision Making, Educational Psychologist, 40(1), 13-25.

Rimmele, R. (2002). Videograph. Multimedia-Player zur Kodierung von Videos [Videograph. Multi-media Player for Video Coding]. Kiel: IPN.

Roth, K.J., Druker, S.L., Garnier, H., Lemmens, M., Chen, C., Kawanaka, T., Rasmussen, D.; Trubacova, S., Warvi, D., Okamoto, Y., Gonzales, P., Stigler, J., \& Gallimore, R. (2006). Teaching Science in Five Countries: Results From the TIMSS 1999 Video Study. Washington, DC: U.S. Department of Education.

Seidel, T., Prenzel, M., \& Kobarg, M. (Eds.), (2005). How to Run a Video Study: Technical Report of the IPN Video Study. Münster: Waxmann Verlag.

Seymour, J.R. \& Lehrer, R. (2006). Tracing the Evolution of Pedagogical Content Knowledge as the Development of Interanimated Discourses. The Journal of the Learning Sciences, 15(4), 549-582.

Shulman, L.S. (1986). Those who Understand: Knowledge Growth in Teaching. Educational Researcher, 15(2), 4-14.

Shulman, L.S. (1987). Knowledge and Teaching: Foundations of the New Reform. Harvard Educational Review, 57(1), 1-22.

Strauss, A., \& Corbin, J. (1990). Basics of Qualitative Research: Grounded Theory Procedures and Techniques. Newbury Park: Sage.

Tsu, A.B.M. (2003). Understanding Expertise in Teaching. Cambridge: Cambridge University Press.

van Dijk, E.M., \& Kattmann, U. (2007). A research model for the study of science teachers' $P C K$ and improving teacher education. Teaching and Teacher Education, 23, 885-897.

van Driel, J.H., Verloop, N. \& Vos, W. (1998). Developing Science Teacher's Pedagogical Content Knowledge. Journal of Research in Science Teaching, 35(6), 673-695.

van Driel, J.H. , Veal, W.R. \& Janssen, F.J.J.M. (2001). Pedagogical Content Knowledge: An Integrative Component within the Knowledge Base for Teaching. Teaching and Teacher Education, 17, 979-986.

Wilson, S.M., Shulman, L.S. \& Richert, A.E. (1987). 150 Different Ways of Knowing: Representations of Knowledge in Teaching. In J. Calderhead (Ed.), Exploring Teachers'Thinking (pp. 100-124). London: Cassell Educational Limited. 